\section{THU0430 DESCRIPTION AND PROGNOSIS FACTORS OF SYSTEMIC SCLEROSIS-ASSOCIATED INTERSTITIAL LUNG DISEASE OUTCOME ON SERIAL HRCT}

A. Forestier ${ }^{1}$, N. le gouellec ${ }^{2}$, A. duhamel ${ }^{3}$, G. kramer $^{4}$, T. perez $^{5}$, V. sobanski ${ }^{1}$, S. morell dubois ${ }^{1}$, M. lambert ${ }^{1}$, P.-Y. hatron ${ }^{1}$, E. hachulla ${ }^{1}$, H. behal ${ }^{3}$, R. matran ${ }^{5}$, D. launay ${ }^{6}, \mathrm{M}$. remy jardin ${ }^{4} .{ }^{1}$ medecine interne et immunologie clinique, chru lille, lille; ${ }^{2}$ internal medicine, $\mathrm{CH}$ valencienne, valencienne; ${ }^{3} \mathrm{UDSL}$, EA2694; ${ }^{4}$ imagerie thoracique; ${ }^{5}$ explorations fonctionnelles respiratoires; ${ }^{6}$ internal medicine, chru lille, lille, France

Background: Interstitial lung disease (ILD) is a leading cause of morbidity and mortality in systemic sclerosis (SSc). While factors associated with the presence of ILD in SSc (SSc-ILD) are identified, those associated with ILD outcome are still debated and studies assessing the evolution of SSc-ILD on HRCT are scarce. Yet, it is important to identify patients at risk of SSc-ILD worsening because those patients are thought to benefit the most from immunosuppressants.

Objectives: Thus, the aims of our study were: to describe the evolution of HRCT extension and patterns of SSc-ILD, to identify baseline prognosis factors of ILD outcome on serial HRCT and to investigate whether the evolution of pulmonary function tests (PFTs) parameters correlated with the evolution on HRCT.

Methods: We included 58 SSc patients with HRCT proven ILD, with at least two available HRCT, and collected clinical, biological data and PFT at baseline. We collected all HRCT and PFTs available during follow-up. We modelized PFTs and HRCT evolution using linear mixed model with random coefficients.

Results: Mean ILD extension at baseline was $32.3 \% \pm 28.7 \%$. During a mean follow-up of $5.3 \pm 4.9$ years, we found a significant mean progression of ILD extension of $0.92 \% \pm 0.36 \%$ per year $(p=0.018)$. Male sex, anti-topoisomerase 1 antibodies, diffuse cutaneous SSc were associated with faster progression of ILD extension. Limited ILD according to Goh et al. staging system, and a coarseness score at zero (meaning $100 \%$ of ground glass opacification) were associated with a faster progression of ILD extension. We also found a significant decline of DLCO, FVC and TLC during follow-up. There was a significant correlation between the progression of ILD extension on HRCT and the decline of DLCO, but not with the evolution of FVC.
A

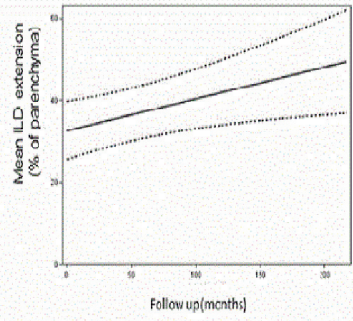

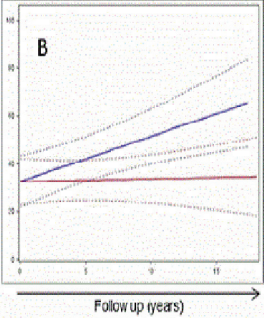

(n) inted cutanowuss:

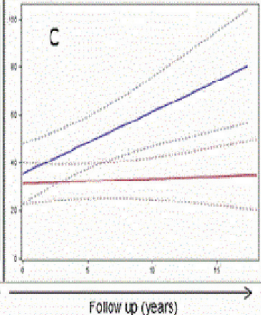

Fôlliow ip (yeari

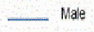

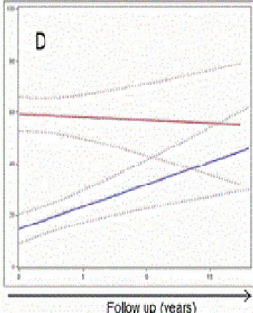
Extensiva L LDestension according 10 Goh et imited enension
Conclusions: Male patients, patients with diffuse SSc/antitopoisomerase 1, patients with less severe and less extensive ILD at baseline were more likely to experiment a faster progression of ILD extension on serial HRCT. To our knowledge, this is the first study that clearly highlighted the diffuse form of SSc/presence of antitopoisomerase 1 as a worsening factor of SSc-ILD on HRCT. FVC might not be the best mirror of ILD progression while DLCO significantly correlated with change in ILD extension. Our study helps to define the profile of patients who are going to experience a progression of ILD on HRCT during follow up.

Disclosure of Interest: None declared

DOI: 10.1136/annrheumdis-2018-eular.5493

\section{THU0431 ARE EXTREMITY TELANGIECTASES RELATED TO SEVERE DISEASE IN SYSTEMIC SCLEROSIS ?}

Y. Yalçınkaya ${ }^{1}$, O. Pehlivan ${ }^{2}$, Z. Ertürk ${ }^{1}$, U. Gazel ${ }^{3}$, A. Aksoy ${ }^{1}$, F. Alibaz-Oner ${ }^{1}$, P. Atagunduz ${ }^{1}$, H. Direskeneli ${ }^{1}$, N. Inanc ${ }^{1} .{ }^{1}$ Department of Internal Medicine, Division of Rheumatology, Marmara University, School of Medicine; ${ }^{2}$ Department of Internal Medicine, Division of Rheumatology, Umraniye Education and Research Hospital; ${ }^{3}$ Marmara University, School of Medicine, Istanbul, Turkey

Background: The number and morphology of telangiectases $(T)$ have been studied in terms of severity and organ involvement in sytemic sclerosis (SSc). T are located more frequently on face and trunk than extremities.

Objectives: We aimed to evaluate the impact of the localisation of $\mathrm{T}$ on different skin areas in addition to number on disease severity of SSc.

Methods: SSc patients fulfilling ACR/EULAR classification criteria (2013) who had the manifestation T were included. The number of $T$ were calculated by using telangiectasia score (TS) (Shah A., et al) and localisation was classified according to presence of T on extremities or not. Simultaneously; ealy, active and late scleroderma patterns (Cutolo et al.) were determined qualitatively and capillary number $(\mathrm{CN})$ was calculated per linear $\mathrm{mm}$ at distal row quantitatively by using nail fold video-capillaroscopy (NVC) in all patients.

Results: In 113 (106 female) SSc patients with T; the mean age was $52 \pm 12$, the duration of follow-up $57 \pm 62$ months, Raynaud and non-Raynaud symptom 10 \pm 8 and $7 \pm 7$ years. Limited cutaneous form was found to be in $77(\% 68)$, ANA positivity in $102(\% 90)$ ve anti-Scl70 positivity in $33(\% 29)$ patients. In SSc patients with TS score $\geq 6$ or extremity $\mathrm{T}$; the duration of non-Raynaud symptom was found to be longer ( $p=0010$ or 0,009$)$, MRSS and activity scores were higher ( $p=0004$ or 0012 and $p=0010$ or 0,009 ) and severity scores of general, peripheral vascular involvement and skin were higher $(p=0022$ or $0,014, p=0030$ or 0025 and $\mathrm{p}=0006$ or 0,02 ), digital ulcers and flexion contractures were more frequent ( $p=0008$ or 0035 and $p=0027$ or 0,032 ), late NVC pattern was more frequent and $C N$ was lower $(p=0001$ or 0003 and $p=0001$ or 0,007$)$. When patients were classified in 3 groups according to TS and presence of extremity $\mathrm{T}$, differences in terms of organ involvement, disease activity and severity scores and NVC findings were summarised in table 1.

Abstract THU0431 - Table 1. The scores of disease activity, severity and capillaroscopy in SSc patients grouped according to TS and localisation of T.

\begin{tabular}{|c|c|c|c|c|c|}
\hline & $\underset{\substack{\text { All patients } \\
N=113}}{(13}$ & $\begin{array}{c}\mathrm{TS} \leq 6 \\
\quad \leq 6 \\
\text { Extremity } \mathrm{T}(-) \\
\mathrm{N}=7 \mathrm{~T}\end{array}$ & $\begin{array}{c}\mathrm{TS} \leq 6 \\
\begin{array}{c}+ \\
\text { Extremity } \\
\mathrm{N}=11\end{array}\end{array}$ & $\begin{array}{c}\mathrm{TS}>6 \\
+\quad \\
\text { Extremity } \mathrm{T}(+) \\
\mathrm{N}=25\end{array}$ & $\mathrm{P}^{*}$ \\
\hline Duration of non-Raynaud's (year) & $6 \pm 7$ & $6 \pm 6$ & $8 \pm 5$ & $10 \pm 9$ & $\mathrm{P}=0,008$ \\
\hline MRSS & $7,7 \pm 6,5$ & $6 \pm 6$ & $9 \pm 6$ & $11 \pm 9$ & $\mathrm{P}=0,013$ \\
\hline Disease activity score (Valentini) & $1,4 \pm 1,2$ & $0,7 \pm 0,9$ & $1,2 \pm 1,0$ & $1,6 \pm 1,4$ & $\mathrm{P}=0,015$ \\
\hline Disease severity score (Medsger) & $5,6 \pm 3,7$ & $5,3 \pm 4,1$ & $5,9 \pm 2,6$ & $6,4 \pm 2,7$ & $\mathrm{P}=0,024$ \\
\hline severity-general & $0,6 \pm 0,7$ & $0,5 \pm 0,6$ & $0,7 \pm 0,7$ & $1 \pm 0,8$ & $\mathrm{P}=0,050$ \\
\hline severity-PVI & $1,5 \pm 0,8$ & $1,4 \pm 0,8$ & $1,6 \pm 0,5$ & $1,8 \pm 0,8$ & $\mathrm{P}=0,023$ \\
\hline severity-skin & $1,1 \pm 0,5$ & $1 \pm 0,5$ & $1,2 \pm 0,4$ & $1,3 \pm 0,6$ & $\mathrm{P}=0,012$ \\
\hline Clinical findings & $52(\% 46)$ & $29(\% 38)$ & $7(\% 64)$ & $16(\% 64)$ & $\mathrm{P}=0,033$ \\
\hline Flex contr & $16(\% 14)$ & $7(\% 9)$ & $2(\% 18)$ & $7(\% 28)$ & NS \\
\hline renal crisis & $1(\% 1)$ & $0(\%)$ & $1(\% 9)$ & $0(\% 0)$ & $\mathrm{P}=0,010$ \\
\hline Low DLCO & $55(\% 49)$ & $33(\% 44)$ & $7(\% 70)$ & $15(\% 60)$ & NS \\
\hline Fibrosis & $48(\% 43)$ & $28(\% 38)$ & $7(\% 70)$ & $13(\% 52)$ & $\mathrm{P}=0,028$ \\
\hline high PAB & $20(\% 18)$ & $10(\% 13)$ & $2(\% 20)$ & $8(\% 32)$ & $\mathrm{P}=0,034$ \\
\hline IS receivers & $64(\% 57)$ & $39(\% 54)$ & $8(\% 80)$ & $17(\% 68)$ & NS \\
\hline ERA receivers & $30(\% 27)$ & $15(\% 21)$ & $3(\% 33)$ & $12(\% 50)$ & $\mathrm{P}=0,028$ \\
\hline Normal & $7(\% 6)$ & $6(\% 9)$ & $0(\% 0)$ & $0(\% 0)$ & NS \\
\hline Early & $23(\% 20)$ & $19(\% 25)$ & $2(\% 18)$ & $2(\% 8)$ & NS \\
\hline Active & $22(\% 19)$ & $19(\% 25)$ & $1(\% 9)$ & $2(\% 8)$ & NS \\
\hline Late & $62(\% 54)$ & $33(\% 43)$ & $9(\% 82)$ & $21(\% 84)$ & $\mathrm{P}<0,001$ \\
\hline Capillary number & $5,8 \pm 2,0$ & $6,4 \pm 2,1$ & $5 \pm 2$ & $4,9 \pm 1,8$ & $\mathrm{P}<0,001$ \\
\hline
\end{tabular}

Conclusions: Disease duration was shown to be long, disease activity and severity were high and NVC findings were severe in patients with high scores of TS and extremity T. In patients with lower TS the presence of T on extremities was found to be related to severe disease. The number and localisation of $T$ was emphasised as they are easy to evaluate in clinical practice and may be useful in determining severe patients with SSc.

Disclosure of Interest: None declared

DOI: 10.1136/annrheumdis-2018-eular.3996

\section{THU0432 PERICARDIAL EFFUSION IS AN INDEPENDENT FACTOR PREDICTIVE OF SCLERODERMA RENAL CRISIS}

Y. Fujisawa, S. Hara, T. Zoshima, K. Ito, I. Mizushima, H. Fuji, K. Yamada, M. Kawano. Rheumatolody, Kanazawa University Hospital, Kanazawa City, Ishikawa, Japan

Background: Scleroderma renal crisis (SRC) adversely affects renal and patient survival in systemic scleroderma (SSc) [. ${ }^{1,2}$ The survival rate of SRC has been 